TESTIMONIOS DE AFECTO Y AMISTAD

Revista Atlántica-Mediterránea 22, pp. 11-41

BIBLID [2445-3072 (2020) 22, 1-443]

https://doi.org/10.25267/rev_atl-mediterr_prehist_arqueol_soc.2020.v22.06

\title{
TESTIMONIO DE AFECTO Y AMISTAD A ANTONIO SÁEZ ESPLIGARES
}

\section{Eduardo VIJANDE VILA}

Profesor Titular de Prehistoria. Universidad de Cádiz.

Correo electrónico: eduardo.vijande@uca.es

Sirvan estas palabras como homenaje y reconocimiento a la labor patrimonial desarrollada por Antonio Sáez Espligares en San Fernando y en buena parte de la provincia. No voy a extenderme ya que su propio hijo, o compañeros más veteranos, pueden glosar mucho mejor que yo su trayectoria.

Mi relación con Antonio tiene su origen en su última etapa profesional. No puedo precisar el día (ni siquiera el año) en el que lo conocí. Probablemente fue en uno de los Encuentros de Historia de San Fernando celebrados durante mi etapa como estudiante de Historia allá por el cambio de siglo. El Museo Histórico de San Fernando, con Antonio a la cabeza, se erigía por entonces como una de las pocas instituciones que velaban por la defensa de nuestro patrimonio isleño, en el sentido más amplio del término.

Fue en el verano de 2007 cuando empecé a tratar con Antonio de manera más estrecha a raíz de la excavación del poblado neolítico de Campo de Hockey. Y es que si Antonio ha estado presente en el descubrimiento de los hitos arqueológicos más importantes de nuestra provincia (la dama de Cádiz, el teatro romano de Cádiz, los primeros trabajos de documentación gráfica en la Laja Alta, etc.), no podía ser menos en el caso de Campo de Hockey. Fueron sus ojos, entrenados a lo largo de toda una vida dedicada a la arqueología, los primeros en identificar estructuras prehistóricas en uno de los perfiles generados durante el rebaje del terreno. A los pocos días, me encontraba dirigiendo una excavación arqueológica que se prolongó durante casi un año. Pese a que pertenecemos a dos generaciones diferentes nos entendimos a la perfección. Desde el primer día Antonio se ofreció a ayudarnos de forma desinteresada y, como no podía ser de otra manera, no dejamos pasar la oportunidad de contar en el equipo con un profesional con su experiencia y conocimientos. Compartimos momentos únicos como la excavación de "los enamorados" o su complejo traslado al Museo Histórico (Figura 1). Además, mantuvimos numerosas charlas y debates sobre arqueología, pero siempre en un clima de gran aprecio y respeto mutuo. Su carácter afable y tranquilo y nuestra pasión por la arqueología crearon unas condiciones de trabajo inmejorables y, poco a poco, nuestra relación profesional derivó hacia la amistad. Fueron meses de continuo aprendizaje. Y es que Antonio pertenece a esa ya casi extinta generación de "arqueólogos totales", con un dominio muy profundo del registro arqueológico desde la Prehistoria hasta la época Moderna.

Posteriormente, en mis continuas visitas al museo comprendí que Antonio tenía en su cabeza, no solo la arqueología de la ciudad, sino toda su historia. Pocas personas conocen tan profundamente nuestro pasado. Para mí Antonio es el auténtico académico de la historia de San Fernando (aunque ni es cañaílla ni tiene medalla).

Por mucho que se invierta en un museo el éxito del mismo no viene dado por su faraónica o vanguardista arquitectura, sino por el compromiso y profesionalidad de su personal. Antonio desarrolló la mayor parte de su carrera en el museo más modesto de la ciudad, pero era un museo con una gran actividad investigadora. Por sus estrechos pasillos nos cruzábamos a diario arqueólogos, historiadores, archiveros, artistas, fotógrafos, etc. Era un museo pequeño, pero vivo. Y ha sido además, cuna de muy buenos profesionales de la arqueología que actualmente desarrollan su labor en empresas privadas, centros de investigación y universidades nacionales. Antonio fomentó un museo abierto para todo el mundo y, prueba de su carácter afable y humilde, era que atendía por igual a investigadores profesionales o a ciudadanos aficionados.

Como arqueólogo y como cañaílla finalizo dándole las gracias por toda una vida dedicada a la protección, estudio y difusión de nuestro pasado. Deja un gran vacío en la gestión del patrimonio isleño, algo que a los que nos dedicamos a esto nos preocupa enormemente. Pero me quedo con su legado y con esa generación de arqueólogos, entre ellos su hijo, que van a continuar estudiando y protegiendo el patrimonio histórico de nuestra tierra. 


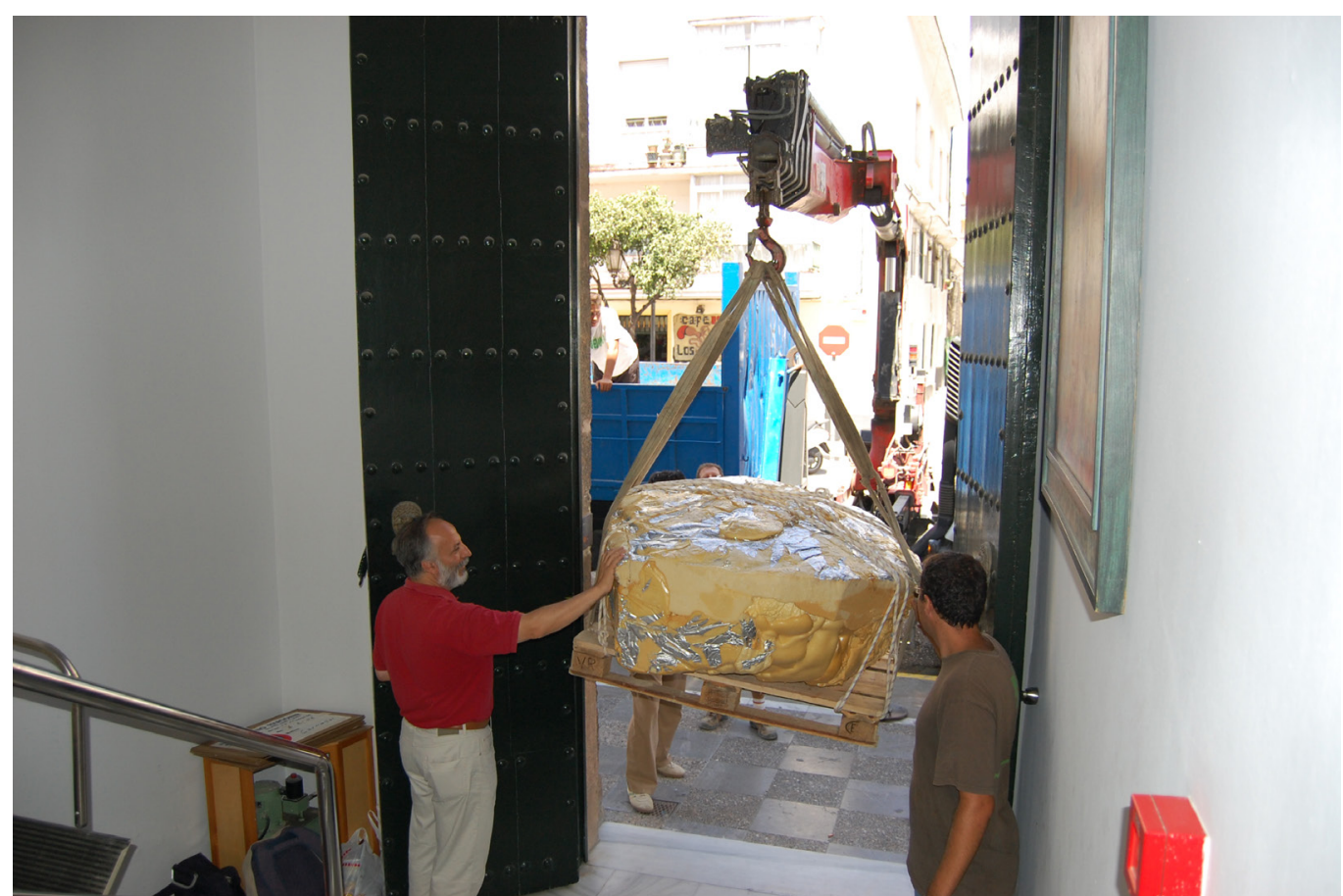

Figura 1. Traslado del enterramiento doble abrazado de la necrópolis neolítica de Campo de Hockey (conocido popularmente como "Los Enamorados") al antiguo Museo Histórico Municipal de San Fernando (calle Real, 63). A la izquierda Antonio Sáez Espligares (Subdirector del Museo) y a la derecha Eduardo Vijande Vila (Director de la intervención arqueológica). 